\title{
Somatization disorder among adolescents in southeast Nigeria: a neglected issue
}

\author{
A. R. C. Nwokocha' ', J. M. Chinawa ${ }^{1,5^{*}}$, V. Onukwuli ${ }^{1}$, A. Ubesie ${ }^{1}$, Appolos Ndukuba², A. T. Chinawa ${ }^{3}$, \\ Elias Aniwada ${ }^{4}$ and Samuel Uwaezuoke ${ }^{1}$
}

\begin{abstract}
Background: Adolescents do present with somatization disorder which is often neglected by pediatricians. This could have serious consequences if not curbed early.

Objectives: This study is aimed at determining the pattern and types of Somatization disorder among adolescents attending secondary schools in south east Nigeria.

Methods: Somatization disorder was investigated among 485 adolescents from mixed schools using a stratified random sampling of adolescents from four secondary schools in southeast Nigeria. The Enugu somatization scale was used to evaluate for presence of somatization in the participants. Statistical analysis was with statistical package for social sciences (SPPS) version 19 (Chicago IL).

Results: A total of 485 adolescents aged 10-19 years were included in this study. The mean age of the respondents was 16.36 with standard deviation (SD) of 3.14 years. Two hundred and fifty-one (51.8\%) had head features, 262 (54.0\%) had body features, 303 (62.5\%) had either head or body features while 210 (43.3\%) had both head and body features. One hundred and thirty-four males (51.3\%) compared to 117 females (52.2\%) reported symptoms consistent with head symptoms $(p=0.038)$. One hundred and eleven males $(42.5 \%)$ compared to 99 females $(44.2)$ reported symptoms related to the head and body $(p=0.137)$ while 135 males $(51.7 \%)$ compared to 127 females $(56.7 \%)$ reported symptoms related to the body $(p=0.925)$. There were significant associations of age in categories with head, body, either head or body as well as both head and body features (all p value $<0.001$ ).
\end{abstract}

Conclusions: Psychosomatic problems do exist and may be on the rise among adolescents.

Keywords: Psychosomatic disorder, Adolescents, Secondary schools, Nigeria

\section{Background}

Somatization disorder (SD) as a psychiatric diagnosis became entrenched in the DSM-IV (2000) to reflect the condition hitherto known as Briquet's syndrome which is a polysymptomatic condition that starts before the age of 30 years and extends for a long time [1]. It is characterized by pains, gastrointestinal, genitourinary and pseudoneurological symptoms. In the ICD-10, somatization is

\footnotetext{
*Correspondence: josephat.chinawa@unn.edu.ng

${ }^{5}$ Department of Pediatrics, UNTH, PMB 01129, Enugu 400001, Enugu State, Nigeria

Full list of author information is available at the end of the article
}

defined as multiple, recurrent and frequently changing physical symptoms usually present for several years; (at least 2 years) before the patient is referred to a psychiatrist [2]. There are significant departures from the DSMIV categorization which identified somatization disorder, hypochondriasis, pain disorder, and undifferentiated somatoform disorder. All these are now included under the heading of SD [2]. In addition, the symptoms need no longer to be medically unexplained but may or may not be associated with another medical condition. This implies that adolescents who had organic co- morbidities who were previously excluded under DSM-IV can now 
be included in the diagnosis of SD and be considered for appropriate treatment.

It has been generally believed that this disorder occurs predominantly in non-western and developing societies. However, there is growing evidence that suggests that somatic disorder is a hidden malaise that presents in large numbers all over the world, but is often under diagnosed [3]. This behavioral problem among adolescents is common in all cultural groups and societies, especially in the primary care [4]. With the burden of this problem in view, it is believed that it will give the pediatric adolescent specialist some hint that his patient, who may deny any psychic distress, is actually under some unbearable psychological states [5]. It is seen that when the adolescents is diagnosed with somatic problems, it makes the adolescent withdrawn from his peers and is often been stigmatized as been abnormal and psychotic. Thus the Nigerian adolescent cannot afford to even discuss this problem with his parents or teachers since he/she may be forced to cope with somatic distress for a long time [5-9].

Reported prevalence of somatization varies depending on the criteria. It has been noted that about $50 \%$ of adolescents who attend pediatric clinic will complain of medically unexplained symptoms with significant functional and emotional impairment. Such adolescents pose heavy burdens on the healthcare system through frequent utilization of health resources and hospitalizations, specialist consultations, unnecessary investigations, and treatments $[10,11]$. In addition to the negative impact of the associated co-morbidities, family conflict and school absenteeism, failure to make accurate and timely diagnosis often results in multiple referrals, repeated unnecessary diagnostic tests, unjustified and potentially harmful treatments including medication trials and even surgeries, and the perpetuation of the belief of underlying organic illness [12].

Accurate diagnosis and treatment of adolescent somatic problem can make a great difference in patients' life and in pediatrician or physician satisfaction. These treatment approaches involve a multidisciplinary approach which aims at targeting the adolescent/family's understanding of the mind-body relationship and their acceptance of the bio-psycho-social formulation and treatment [13]. However, Ohaeri and Olatawura have observed the resilience of SD to physical methods of treatment [14].

Managing somatization disorder often poses challenges to the physician. The reasons would include ignorance of the condition [15]. As Ndukuba et al. [16] noted, there is a poor knowledge of conversion disorders by pediatricians in Nigeria and this could delay identification of children and adolescents with somatoform disorders. In addition, the drive to rule out organic disease, the fear of missing organic diseases and the poverty of skills in exploring psychological issues by most physicians could contribute to the difficulties faced by them in managing an adolescent presenting with this condition. Interestingly, Smith [17] had shown that the health care costs declined by $53 \%$ when primary care physicians treated their somatizing patients appropriately.

Considering that adolescents make up a significant proportion of the Nigerian population and that a recent study of adults with mental health disabilities documented that their problems reportedly started in early adolescence or around 14 years of age and given the serious negative impact of mental health problems, there is need to evaluate children and adolescents for somatization disorder, a very common mental health problem [18]. This is particularly so in south-east Nigeria where studies are scanty that have focused on childhood and adolescent somatic disorders.

This study is aimed at determining the types somatization disorder among adolescents attending secondary schools in South east Nigeria. It is hoped that this study will add to the knowledge of this disorder and will alert the pediatrician of its existence among children and adolescent age group.

\section{Methods \\ Setting}

The study was carried out among adolescents in four secondary schools in Enugu and Ebonyi States of south east Nigeria.

\section{Study design}

A descriptive cross sectional study was used to identify the pattern and types of PSDs among adolescents attending secondary schools in South east Nigeria.

\section{Sampling}

Four secondary schools were selected in Enugu and Ebonyi metropolis through stratified random sampling method. The schools were stratified using state and nature of school that is whether unisex or mixed schools. Two same gender schools and two co-educational schools were utilized. The schools selected were proportionately allocated number of participants. From a total 3654 adolescent students in all chosen schools, 485 adolescents were selected using random sampling.

\section{Data collection}

A pretested self-administered Enugu somatization scale (ESS) developed by Ebigbo [6] was used for this study. The Enugu somatization scale is a culture specific screening scale that measures the culture-bound illness somatization. This instrument was developed bearing in mind the shortcomings or uncertainties that accompanies the use of western methods of assessment techniques and also to figure out the nature of psychological problem 
behind somatic symptoms as presented by Enugu, Nigerian patients. The ESS is a 65 -item scale. The scale was found to distinguish patients from normals [6]. It has two sub-scales. The first is the HEAD subscale, captured by items 1-23, while the BODY subscale is captured by items 24-65. The ESS has a dichotomous response options which are YES and NO. It has been cross-validated with neurotic illness questionnaire (NIQ) in India where the ESS was found to correlate significantly with NIQ [7]. The ESS is a dichotomous response scale with YES and NO representing the dichotomies. A score of 1 is assigned to any Yes while a score of 0 is assigned to any NO response. With the exception of item 55 which is positively worded, all other items on the ESS are scored by the number of positive responses. Interpretation of score was based on the norm produced by the author. See Table 1 .

The questionnaires were completed by the students under strict examination conditions during class hours after explanation of the purpose of the study. Confidentiality was assured by informing the respondents not to write their names on the questionnaires. The class teachers were excluded from the class during the exercise to avoid their possible influence.

\section{Data analysis}

Statistical analysis was with statistical package for social sciences (SPPS) version 19 (Chicago IL). Chi square test was used to test for statistical association of age in categories as well as sex with presence or absence of psychosocial disorder. Binary logistic regression was used to control for confounding. All reported $\mathrm{p}$ values are 2 -sided and values $<0.05$ were assumed as significant.

\section{Ethical consideration}

Ethical approval for the study was obtained from the Health Research Ethics Committee of the University of Nigeria Teaching Hospital, Ituku-Ozalla, Enugu. Permission and approval were obtained from post primary education board of each state as well as from principals of each school studied. Assent was obtained from the students after a detailed explanation of the study objectives, procedures, risks and benefits. Informed consent was

Table 1 Norms for the Enugu summarization scale

\begin{tabular}{lll}
\hline & \multicolumn{2}{l}{ Students } \\
\cline { 2 - 3 } & Male & Female \\
\hline Head & 3.58 & 4.12 \\
Mean scores & & \\
Body & 7.22 & 7.73 \\
Mean scores & 4.40 & 2.81 \\
\hline
\end{tabular}

also obtained from the principals of the selected schools, who acted as the legal guardians of the students.

This article is aimed at determining the types and factors associated with PSDs among adolescents attending secondary schools in South east Nigeria. Subjects who gave consent were included in this study while those without consent and those with obvious psychiatric disorders were excluded.

\section{Results}

\section{Demography}

A total of 485 adolescents aged 10-19 years were included in this study. Their median age was 16 (1QR: $15-17)$ years. Two hundred and sixty-one $(53.8 \%)$ were males. Table 2 shows the socio-demographic characteristics of respondents. The mean age of the respondents was 16.36 with standard deviation (SD) of 3.14 years. Majority were aged $15-19$ years.

\section{Prevalence of psychosocial disorder}

Table 3 shows the distribution and pattern of Somatization disorder. Two hundred and fifty-one (51.8\%) had

Table 2 Socio-demographic characteristics of respondents

\begin{tabular}{lll}
\hline Socio-demographic characteristics & \multicolumn{2}{l}{ Total $(\mathbf{N})=\mathbf{4 8 5}$} \\
\cline { 2 - 3 } & Frequency (n) & Percent (\%) \\
\hline Age in categories (years) & & 13.2 \\
$10-14$ & 64 & 86.8 \\
$15-19$ & 421 & \\
Mean (SD) & $16.36(3.14)$ & \\
Sex & & 46.2 \\
Female & 224 & 53.8 \\
Male & 261 & \\
\hline
\end{tabular}

Table 3 Distribution and pattern of somatization disorder

\begin{tabular}{|c|c|c|}
\hline \multirow[t]{2}{*}{ Somatization disorder } & \multicolumn{2}{|l|}{ Total $(\mathrm{N})=485$} \\
\hline & Frequency (n) & Percent (\%) \\
\hline \multicolumn{3}{|l|}{ Head } \\
\hline Absence & 234 & 48.2 \\
\hline Presence & 251 & 51.8 \\
\hline \multicolumn{3}{|l|}{ Body } \\
\hline Absence & 223 & 46.0 \\
\hline Presence & 262 & 54.0 \\
\hline \multicolumn{3}{|l|}{ Either head or body } \\
\hline Absence & 182 & 37.5 \\
\hline Presence & 303 & 62.5 \\
\hline \multicolumn{3}{|l|}{ Both head and body } \\
\hline Absence & 275 & 56.7 \\
\hline Presence & 210 & 43.3 \\
\hline
\end{tabular}


head features, 262 (54.0\%) had body features, 303 (62.5\%) had either head or body features while 210 (43.3\%) had both head and body features.

\section{Gender and somatization disorder}

One hundred and thirty-four males (51.3\%) compared to 117 females (52.2\%) reported symptoms consistent with head symptoms $(\mathrm{p}=0.038)$. One hundred and eleven males (42.5\%) compared to 99 females (44.2) reported symptoms related to the head and body $(\mathrm{p}=0.137)$ while 135 males (51.7\%) compared to 127 females (56.7\%) reported symptoms related to the body $(\mathrm{p}=0.925)$ as depicted in Table 4.

\section{Age and somatization disorder}

The median age among adolescents that had somatization disorder was 16 (13-19) years compared to 15 (range: 10-19) years among those without somatization disorder $(\mathrm{U}=.18555 .0, \mathrm{p}<0.001)$. The median age of adolescents that reported head symptoms was 16 (range: 10-19) years compared to 15 (range: 10-19) among those without head symptoms $(\mathrm{U}=.21873 .0, \mathrm{p}=0.002)$. Similarly, the median age among adolescents that reported body symptoms was 16 (range: 13-19) years compared to 15 (range: 10-19) among those without body symptoms $(\mathrm{U}=.21014 .0, \mathrm{p}<0.001)$. The proportion of adolescents that reported somatization symptoms across the various ages is shown in Table 4.

Table 4 shows the relationship between socio-demographic characteristics and somatization disorder. There were significant associations of age in categories with head, body, either head or body as well as both head and body features (all $\mathrm{p}$ value $<0.001$ ). The respondents that were aged 15-19 years were; about 4 times (AOR 4.2; 95\% CI 2.7-7.7) likely to have head features, about 5 times (AOR 4.7; 95\% CI 2.5-8.6) likely to have body

Table 4 Relationship between socio-demographic characteristics and somatization disorder

\begin{tabular}{|c|c|c|c|c|}
\hline \multirow[t]{3}{*}{ Socio-demographics } & \multicolumn{2}{|c|}{ Total $(\mathrm{N})=\mathbf{4 8 5}$} & \multirow{3}{*}{$\begin{array}{l}\text { Bivariate analysis } \\
x^{2}(p \text { value })\end{array}$} & \multirow{3}{*}{$\begin{array}{l}\text { Multivariate analysis } \\
\text { AOR }(95 \% \mathrm{Cl})\end{array}$} \\
\hline & Absence & Presence & & \\
\hline & Freq (\%) & Freq (\%) & & \\
\hline \multicolumn{5}{|l|}{ Head } \\
\hline \multicolumn{5}{|l|}{ Age categories (years) } \\
\hline $10-14$ & 49 (76.6) & $15(23.4)$ & $23.674(0.000)$ & 1 \\
\hline $15-19$ & $185(43.9)$ & $236(56.1)$ & & $4.2(2.7-7.7)$ \\
\hline \multicolumn{5}{|l|}{ Sex } \\
\hline Female & 107(47.8) & $117(52.2)$ & $0.038(0.845)$ & NA \\
\hline Male & $127(48.7)$ & 134(51.3) & & \\
\hline \multicolumn{5}{|l|}{ Body } \\
\hline \multicolumn{5}{|l|}{ Age categories (years) } \\
\hline $10-14$ & $49(76.6)$ & $15(23.4)$ & $27.764(0.000)$ & 1 \\
\hline $15-19$ & $174(41.3)$ & $247(58.7)$ & & $4.7(2.5-8.6)$ \\
\hline \multicolumn{5}{|l|}{ Sex } \\
\hline Female & $97(43.3)$ & $127(56.7)$ & $1.200(0.273)$ & NA \\
\hline Male & $126(48.3)$ & $135(51.7)$ & & \\
\hline \multicolumn{5}{|l|}{ Head or body } \\
\hline \multicolumn{5}{|l|}{ Age categories (years) } \\
\hline $10-14$ & $45(70.3)$ & $19(29.7)$ & $33.807(0.000)$ & 1 \\
\hline 15-19 & $137(32.5)$ & $284(67.5)$ & & $4.9(2.8-8.8)$ \\
\hline \multicolumn{5}{|l|}{ Sex } \\
\hline Female & $79(35.3)$ & $145(64.7)$ & $0.905(0.341)$ & NA \\
\hline Male & $103(39.5)$ & $158(60.5)$ & & \\
\hline \multicolumn{5}{|l|}{ Head and body } \\
\hline \multicolumn{5}{|l|}{ Age categories (years) } \\
\hline $10-14$ & $53(82.8)$ & $11(17.2)$ & $20.475(0.000)$ & 1 \\
\hline $15-19$ & $222(52.7)$ & $199(47.3)$ & & $4.3(2.2-8.5)$ \\
\hline \multicolumn{5}{|l|}{ Sex } \\
\hline Female & $125(55.8)$ & $99(44.2)$ & $0.137(0.712)$ & NA \\
\hline Male & $150(57.5)$ & $111(42.5)$ & & \\
\hline
\end{tabular}


features, about 5 times (AOR 4.9; 95\% CI 2.8-8.8) likely to have either head or body features and about 4 times (AOR 4.3; 95\% CI 2.2-8.5) likely to have both head and body features than those aged $10-14$ years.

\section{Discussion}

The symptoms of psychosomatic disorders usually begin during adolescence or early adulthood and are characterized by many vague physical complaints. Any part of the body may be affected, although the symptoms and their frequencies vary. Common symptoms of this disorder among adolescents are headaches, nausea and vomiting, abdominal pain, diarrhea or constipation, fatigue, fainting, dizziness, sleeping problems, and nervousness. The most frequently seen symptoms among adolescents should be differentiated from psychosomatic disorders seen among adults [19].

Fifty-one point eight percent (51.8\%) of these adolescents with this disorder reported symptoms related to the head while 54\% reported symptoms involving the body and $62.5 \%$ had either head or body features while $43.3 \%$ had both head and body features. This high prevalence is similar to that obtained by Ibeziako et al. [11] who reported a prevalence of $50 \%$ but at variance with that of Gureje et al. [4] who found Nigerians to have less prevalence of somatization compared to Latin Americans. The prevalence obtained in this study is also higher than that of Arnold et al. [20] who reported a low prevalence of $17 \%$ in his study. Abdulbari et al. [21] also noted a prevalence rate of $23.9 \%$ among Qatari adults. Cultural and geographic construct as well as sample size, methodology and differences due to developmental age could also account for this variations in prevalence.

During the last decade, studies in several countries have shown that the proportion of adolescents with psychosomatic complaints (PSC) increased [5-9]. In Japan there is a considerable rise in the number of children presenting with psychosomatic disorders [22, 23]. The main symptoms in these children include headache, abdominal pain, and poor early rising. Children having two or more symptoms were reported to range about $20-30 \%$. Pupils who come to school infirmaries with physical symptoms related to psychosomatic disorders have increased to more than $15 \%$ per week $[24,25]$.

It is not clear therefore whether the high prevalence found in this study reflects rising incidence of psychopathologies among the adolescent population. Could it be that these social and cultural changes are beginning to take a toll on the mental health of the adolescents?

The strength of this study is that it utilized an instrument developed locally, which considered the cultural issues specific to the region. One would therefore expect the respondents to understand the items of the instrument well and thus respond appropriately. On the other hand, it is likely that social desirability bias on the part of the respondents could have contributed to the high rates of endorsement seen in this study.

That nearly same proportion of participants that had symptoms referred to the head also had symptoms referred to the body could reflect the poly-symptomatic nature of the condition.

This study did not find any gender difference in the endorsement of symptoms except that males presented with head symptoms more than females. This is in agreement with other studies that have reported the obliteration of gender differences in most psychiatric disorders during adolescence [26].

This study finds that participants with symptoms were older than those without symptoms. The reason for this is not clear but considering that the condition is characterized by its chronic nature, it is likely that the number of adolescents with the condition would increase with increasing age.

The above discussion goes to portend the fact that a gamut of policy initiatives is needed to adequately provide for effective early mental health services for adolescents and their families. This policy must range from enhanced awareness of mental health issues and points of service access, development of effective techniques for identification and intervention, destigmatization of mental health problems, preparing pediatric psychologists for Collaborative roles in early childhood mental health services, funding for early childhood mental health service needs, family involvement in determination of service needs and policies and research aimed at broadening the range of effective diagnostic and intervention [27-29]. Apart from these policies, we also recommend rotations in child psychiatry for pediatric residents as an optional elective posting.

This study is limited by the fact that self-rated questionnaire was used. The response could be subject to social desirability bias. Moreover, the instrument being dichotomous makes it difficult to rate the severity of the symptoms. However, the strength of the study is in using a locally developed instrument that is culturally acceptable. This study contributed in highlighting a possible rise in prevalence of somatization disorder in this culture and the need to carry out more detailed study on this issue in the nearest future (Additional file 1).

\section{Conclusion}

Psychosomatic problems do exist and may be on the rise among adolescents.

\section{Additional file}

Additional file 1. Strobe statement checklist. 


\section{Abbreviations}

SD: somatization disorder; ESS: Enugu somatization scale; SPSS: statistical package for social sciences program.

\section{Authors' contributions}

JMC, ARN, NAC, AU, VO and sATC contributed to the conception, writing and proof reading of this manuscript. JMC contributed to writing of the manuscript. All authors proofread the article. All authors read and approved the final manuscript.

\section{Author details \\ ${ }^{1}$ Department of Pediatrics, College of Medicine, University of Nigeria, Univer- sity of Nigeria/Teaching Hospital (UNTH), Ituku-Ozalla, Enugu State, Nigeria. ${ }^{2}$ Department of Psychological Medicine, University of Nigeria, University of Nigeria/Teaching Hospital (UNTH), Ituku-Ozalla, Enugu State, Nigeria. ${ }^{3}$ Department of Community Medicine, ESUT Teaching Hospital, Enugu, Enugu State, Nigeria. ${ }^{4}$ Department Community Medicine, College of Medi- cine, University of Nigeria, University of Nigeria/Teaching Hospital (UNTH), Ituku-Ozalla, Enugu State, Nigeria. ${ }^{5}$ Department of Pediatrics, UNTH, PMB 01129, Enugu 400001, Enugu State, Nigeria.}

\section{Acknowledgements}

We acknowledge Miss Carol that helped in data entering. We also acknowledge the adolescents who gave us consent to carry out this work.

\section{Competing interests}

The authors declare that they have no competing interests.

\section{Availability of data and materials}

All the data supporting our findings is contained within the manuscript. Moreover, information on supplementary data is available on http://www. mentalhealth.va.gov/community...ders/docs/PCPTSD_Screen.pdf.

\section{Consent to participate}

Informed verbal consent was also granted by the subjects, before enrolling them into the study.

\section{Consent to publish}

Not applicable.

\section{Ethical approval}

Ethical clearance was obtained from the Ethics Committee of the University of Nigeria Teaching Hospital Enugu.

\section{Funding}

No current external funding sources for this study. We bore all expenses accrued from this study. We have no sponsor.

\section{Strength and weaknesses of the study}

The sample has its strength in the sample size and number of adolescents selected. This is also first time this study is carried out among adolescents in this vicinity. The weakness of this study lies in the fact that a cross-sectional survey was done. A longitudinal study would have helped to follow up adolescents with psychosomatic disorders over a long time.

\section{Publisher's Note}

Springer Nature remains neutral with regard to jurisdictional claims in published maps and institutional affiliations.

Received: 18 April 2017 Accepted: 4 September 2017

Published online: 21 September 2017

\section{References}

1. American Psychiatric Association. Diagnostic and statistical manual of mental disorders. 4th ed. Washington, DC: American Psychiatric Association; 2000.
2. American Psychiatric Association. Diagnostic and statistical manual of mental disorders. 5th ed. Washington, DC: American Psychiatric Association; 2013.

3. Isaac M. Somatization-a culture-bound or universal syndrome? J Mental Health. 1996:5:219-22.

4. Gureje O, Simon GE, Ustun TB, Goldberg DP. Somatization in cross-cultural perspective: a World Health Organization study in primary care. Am J Psychiatry. 1997;154:989-95.

5. Ebigbo PO. A cross sectional study of Nigerian females using the Enugu Somatization Scale. Cult Med Psychiatry. 1986;10:167-85.

6. Graber JA, Lewinsohn PM, Seeley JR, Brooks-Gunn J. Is psychopathology associated with the timing of pubertal development? J Am Acad Child Adolesc Psychiatry. 1997;36(12):1768-76.

7. Ebigbo PO, Janakiramiah N, Kumaraswamy N. Somatization in cross cultural perspective. In: Peltzer K, Ebigbo PO, editors. Clinical Psychology in Africa. Enugu: Chuka printing Company Ltd; 1989. p. 233-50.

8. Nichter M. Idioms of distress: alternatives in the expression of psychosocial distress: a case study from south India. Cult Med Psychiatr. 1982;5:379-408.

9. Ebigbo PO. The development of a culture-specific (Nigeria) screening scale of somatic complaints indicating psychiatric disturbance. Cult Med Psychiatry. 1982;6:29-43.

10. Kirmayer LJ, Young A. Culture and somatization: clinical, epidemiological, and ethnographic perspectives. Psychosom Med. 1998;60:420-30.

11. Ibeziako P, Bujoreanu S. Approach to psychosomatic illness in adolescents. Curr Opin Pediatr. 2011;23:384-9.

12. Gupta A, Lang AE. Psychogenic movement disorders. Curr Opin Neurol. 2009;22:430-6.

13. Lopes de Mello L. 2010. Psychosomatic disorders. In: Stone JH, Blouin M, editors. International encyclopedia of rehabilitation. http://cirrie.buffalo. edu/encyclopedia/en/article/139/. Accessed 24 Aug 2015.

14. Ohaeri JU, Olatawura MO. The resilience of Somatization disorder to physical methods of treatment. Psychopathol Afr. 1988:22:65-78.

15. Quill T. Somatization disorder: one of medicines' blind spots. JAMA. 1985;254:3075-82.

16. Ndukuba AC, Ibekwe RC, Odinka PC, Muomah RC, Nwoha SO, Eze C Knowledge of conversion disorder in children by pediatricians in a developing country. Niger J Clin Pract. 2015;18:534-7.

17. Smith RG, Monson R, Ray D. Psychiatric consultation in somatization disorder. N Engl J Med. 1986;14:1407-13.

18. Kessler RC, Berglund P, Demler O. Lifetime prevalence and age-of-onset distributions of DSM-IV disorders in the National Comorbidity Survey Replication. Arch General Psychiatry. 2005;62:593-602.

19. Brill SR, Patel DR, MacDonald E. Psychosomatic disorders in pediatrics. Indian J Pediatr. 2001;68:597-603.

20. Arnold IA, De Waal MWM, Eekhof JAH, Assendelft WJJ, Spinhoven P, van Hemert AM. Medically unexplained physical symptoms in primary care: behavioral treatment by the family physician. Psychosomatics. 2009:50:515-24.

21. Abdulbari B, Suhaila G, Tuna B. Gender differences in prevalence of somatoform disorders in patients visiting primary care centers. J Prim Care Community Health. 2010;1:37-42.

22. Takata Y. Research on psychosomatic complaints by senior high school students in Tokyo and their related factors. Psychiatry Clin Neurosci. 2001;55:3-11.

23. Takahashi T, Watanabe H, Matsuo N. Psychosomatic disorders in children: an emerging challenge to health care in Japan. Pediatr Int. 2002;44:153-6.

24. Aro H. Life stress and psychosomatic symptoms among 14 to 16 -year old Finnish adolescents. Psychol Med. 1987;17:191-201.

25. Sawamura R, Tanaka H, Terashima S, Takenaka Y, Ashikaga M, Chihara S, Tanaka T. Differencebetween children's self-recognition and their parents'. Biopsychosoc Med. 2003;43:383-384.

26. Francis $C$, Arthur B. A systematic review of the epidemiology of somatisation disorder and hypochondriasis. J Psychosom Res. 2004;56:391-408.

27. Serna L, Nielsen E, Lambros K, Forness S. Primary prevention with children at risk for emotional or behavioral disorders: data on a universal intervention for Head Start classrooms. Behav Disord. 2000;26:70-84. 
28. Ramey C, Ramey S. Early intervention and early experience. Am Psychol. 1998;53:109-20.

29. Pottick KJ, Warner LA. Update: latest findings in children's mental health. Policy report submitted to the Annie E. Casey Foundation. Vol.
1. New Brunswick, NJ: Institute for Health, Health Care Policy, and Aging Research, Rutgers University. More than 115,000 disadvantaged preschoolers receive mental health services; 2002.

\section{Submit your next manuscript to BioMed Central} and we will help you at every step:

- We accept pre-submission inquiries

- Our selector tool helps you to find the most relevant journal

- We provide round the clock customer support

- Convenient online submission

- Thorough peer review

- Inclusion in PubMed and all major indexing services

- Maximum visibility for your research

Submit your manuscript at www.biomedcentral com/submit
() Biomed Central 